\title{
A NEW APPROACH IN THE DEVELOPMENT AND ANALYSIS OF THE LANDSLIDE SUSCEPTIBILITY MAP OF THE HILLSLOPES OF BUJUMBURA, BURUNDI
}

\author{
Desire Kubwimana \\ Geosciences, Water and Environment Laboratory ${ }^{l}$ \\ Research Center in Natural Sciences and the Environment (CRSNE) ${ }^{2}$ \\ desire.kubwimana@ub.edu.bi \\ Lahsen Ait Brahim \\ Geosciences, Water and Environment Laboratory ${ }^{l}$ \\ laitbrahim@gmail.com \\ Abdellah Abdelouafi \\ Geosciences, Water and Environment Laboratory ${ }^{l}$ \\ abdelouafiab@gmail.com \\ ${ }^{1}$ Mohammed V University in Rabat \\ Ibn Batouta ave., Rabat, Morocco, 10100 \\ ${ }^{2}$ University of Burundi \\ UNESCO ave., Bujumbura, Republic of Burundi, 1550
}

\begin{abstract}
As in other hilly and mountainous regions of the world, the hillslopes of Bujumbura are prone to landslides. In this area, landslides impact human lives and infrastructures. Despite the high landslide-induced damages, slope instabilities are less investigated. The aim of this research is to assess the landslide susceptibility using a probabilistic/statistical data modeling approach for predicting the initiation of future landslides. A spatial landslide inventory with their physical characteristics through interpretation of high-resolution optic imageries/aerial photos and intensive fieldwork are carried out. Base on in-depth field knowledge and green literature, let's select potential landslide conditioning factors. A landslide inventory map with 568 landslides is produced. Out of the total of 568 landslide sites, $50 \%$ of the data taken before the 2000 s is used for training and the remaining $50 \%$ (post-2000 events) were used for validation purposes. A landslide susceptibility map with an efficiency of $76 \%$ to predict future slope failures is generated. The main landslides controlling factors in ascendant order are the density of drainage networks, the land use/cover, the lithology, the fault density, the slope angle, the curvature, the elevation, and the slope aspect. The causes of landslides support former regional studies which state that in the region, landslides are related to the geology with the high rapid weathering process in tropical environments, topography, and geodynamics. The susceptibility map will be a powerful decision-making tool for drawing up appropriate development plans in the hillslopes of Bujumbura with high demographic exposure. Such an approach will make it possible to mitigate the socio-economic impacts due to these land instabilities.

Keywords: slope failure, controlling factor, statistical approach, landslide susceptibility, Africa.
\end{abstract}

DOI: $10.21303 / 2461-4262.2021 .001724$

\section{Introduction}

Tropical Africa, especially the East African Rift Valley region is more susceptible to landslides [1]. Heavy rainfalls with rapid weathering partly explain the high distribution of landslides [2]. Moreover, steep topography associated with uplifting, high weathering tropical environment, and tectonic fault systems would be the main cause of slow-moving deep-seated landslides of the region [3].

The mountains region of the North Tanganyika-Kivu Rift (also called NTK Rift) where sit the hillslopes of Bujumbura are characterized by a scarcity of landslides data [4,5]. One of the reasons for this landslide data-scarcity is the low capacity of the local government [6]. Spatial landslides data collection is constrained with persistent clouds and rapid vegetation growth which hinder an obvious interpretation of satellite images/aerial photos [7-9] and the difficult conditions of field accessibility [5].

In addition, the hillslopes of Bujumbura are susceptible to slope failures as shown in regional landslide distribution carried out on the NTK Rift $[4,10]$. However, in these hillslopes, a reliable landslide inventory and accurate landslide susceptibility still lacking. Focussing on local 
context, only 89 landslides have been already inventoried [11]. As a result, landslides damage each year and cause human life losses. The most striking example is the event of 9 February 2014 where more than 70 people died and countless infrastructures were destroyed during clusters of landslides triggered by long-term rains and which developed into debris flash floods. In-depth studies of landslide susceptibility at regional and local levels are needed and will reduce damages.

The susceptibility assessment carried out at the regional scale shows that Rwenzori Mountains (Uganda) are subject to landslide processes [12]. These mountains are located in the NTK rift as the hillslopes Bujumbura with the same geomorphic/dynamic context. Local studies carried on a part of the study $[11,13]$ show the high landslide susceptibility where the steep slope, the weathering gneiss, and the Rift sediments, the fault system are the main geo-environmental landslide drivers.

To carry out this research, let's use a bivariate probabilistic/statistical approach especially the Weights of Evidence another to predict future landslides initiation. This study focuses on the hillslopes of Bujumbura, where landslide destruction/human losses are highly observed in Burundi [14]. Our approach assumes that current landslide susceptibility is not complete due to the underestimation of landslides used during its development. The assumption is based on low input data i. e. landslides used for model processing (only 89 landslides) in the area within more than hundreds of slope failures [11].

The landslide susceptibility map will be, therefore, an effective tool for the civil protection authorities in charge of the early warning system to mitigate the damages and human lives losses. It will be a tool for planners to better grasp high-risk areas where many efforts will be highlighted during land-use management.

\section{Description of the study area}

The study area is located in the western of the East African Rift and the west of Burundi within $491 \mathrm{~km}^{2}$ (Fig. 1). The population is high $\left(>500 \mathrm{inhab} / \mathrm{km}^{2}\right)$ and the highest concentration is on the west side (extension of the city of Bujumbura). The elevation range is between $759 \mathrm{~m}$ to $2467 \mathrm{~m}$ above sea level (a.s.l.) over a distance of $\sim 15 \mathrm{~km}$, which explains the steep topography where slopes reach $76^{\circ}$.

The study area is a humid tropical climate with a wet season (September - May) alternating with the dry season (June - August). The average annual precipitations and temperatures are respectively $1400 \mathrm{~mm}$ and $19^{\circ} \mathrm{C}$. The long rainy season during nine months per year explains a high density of the hydrographic network with active rivers. The region is in an uplifting context. The rivers cross and incise the steep topography, resulting in a high number of landslides and bank erosion [14].

The low topography is located in the far West followed by steep topography associated with recent tectonic uplift with active faults system oriented to North-South [15]. The Eastern is moderate slopes of a relict landscape.

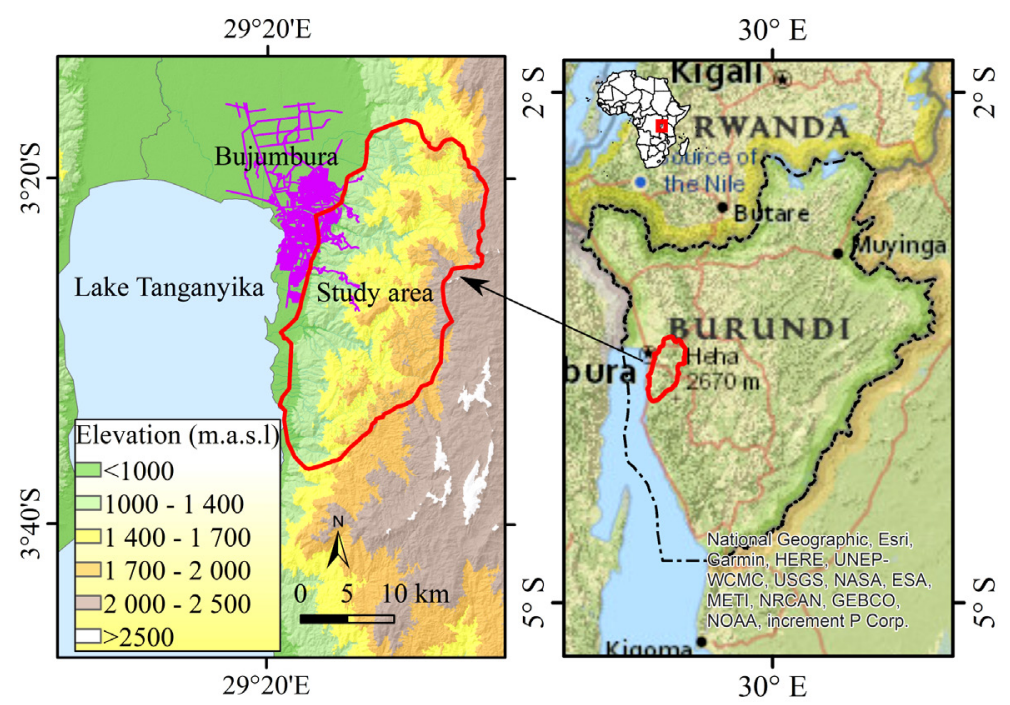

Fig. 1. Location map of the study area 
The lithology is dominated by complex rocks of Precambrian age (gneiss, quartzite, and metaquatzite) with magmatic intrusions (granite, pegmatite) in most of the study area. In the contact of the plain and hillslopes, there are deep rift sediments of the Pleistocene age. Land use/cover is made by three units: (1) the built-up area linked to the rapid extension of the city of Bujumbura as a result of high demographic pressure in the recent decades linked to rural exodus, (2) the forest in the Eastern which is gradually disappearing towards the west to cope with human activities and (3) agricultural land with low to moderate vegetation and scattered trees in the center of the study area.

\section{Methods}

The landslide susceptibility analysis follows the principle of uniformity which states that future landslides will occur under similar conditions to the past [16]. Let's firstly identify potential landslide conditioning factors. The landslides controlling factors was selected based on the literature review and a thorough knowledge of the study area as suggested in [16]. Eight controlling factors are selected including the slope aspect, the curvature, the slope angle, the drainage line density, the elevation, the fault density, the land use/cover, and the lithology (Fig. 2, 3).

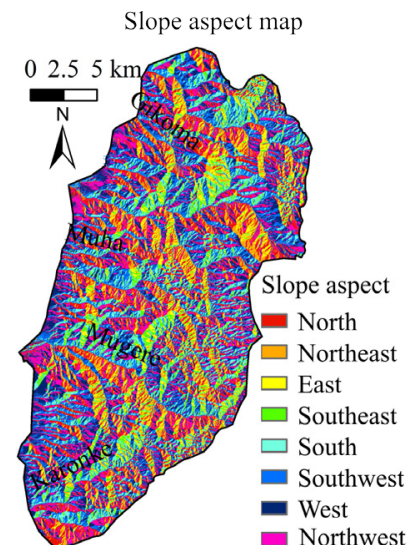

$a$

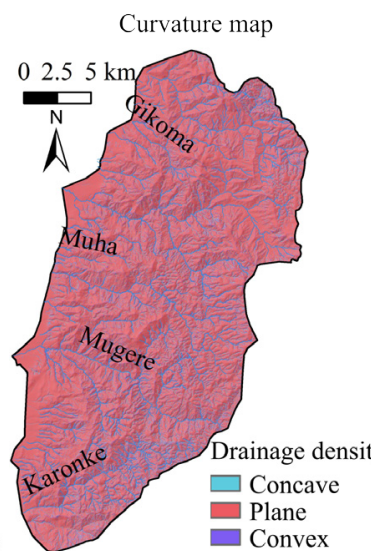

$b$

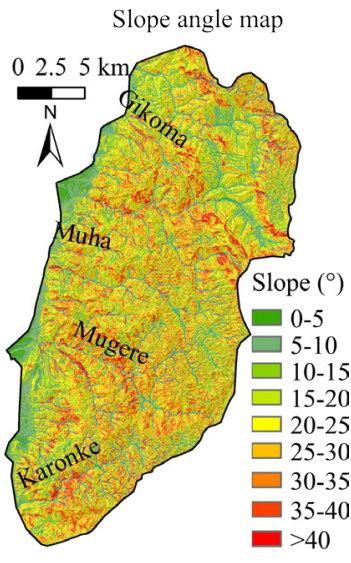

C

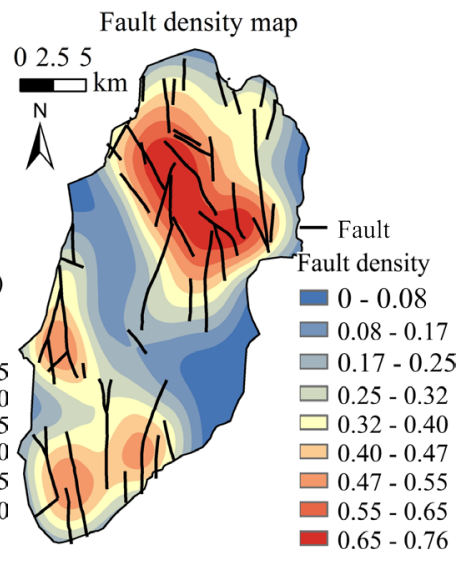

$d$

Fig. 2. Input thematic layers:

$a$ - the slope aspect; $b$ - the curvature; $c$ - the slope angle; $d$ - the drainage density

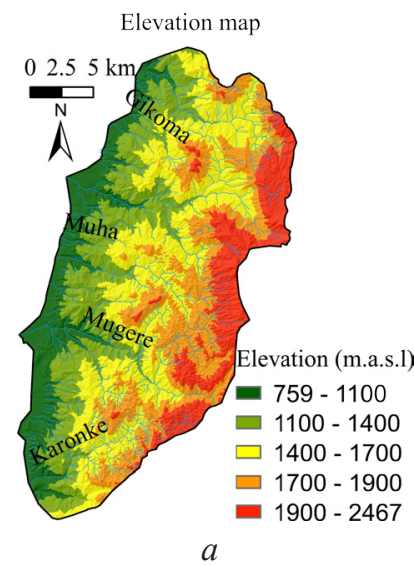

$a$

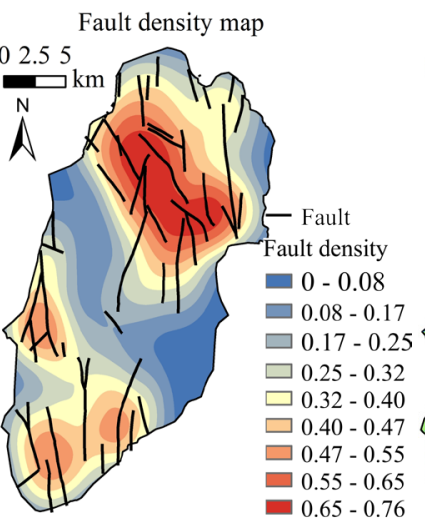

$b$

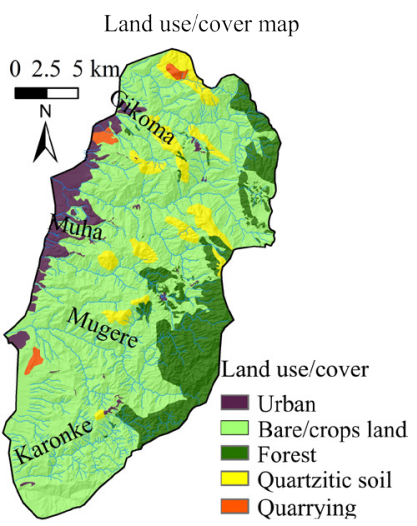

c

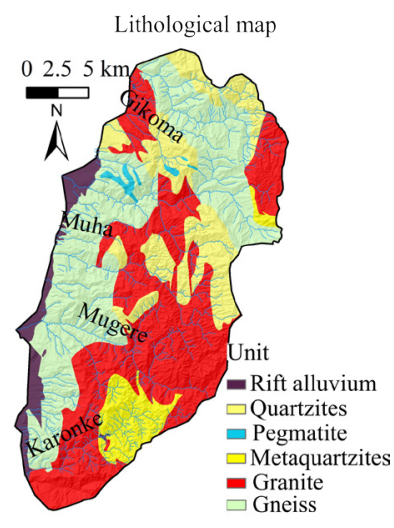

$d$

Fig. 3. Input thematic layers:

$a$ - the elevation; $b$ - the fault density; $c$ - the land use/cover; $d$ - the lithology

The first five (Fig. 2, 3, a, b) were performed with adequate and accurate topographic data, a 10-m Digital Elevation Model (DEM) from orthomosaics provided within the framework of the cooperation between the European Union and the Republic of Burundi in 2012. The 10-m DEM is suitable for the accuracy required within this study. The layers of fault and lithology have been 
obtained by the digitization of the geological map at 1/50000. Land use/cover layer was obtained by digitizing the different classes on aerial ortho-photographs ( $0.5-\mathrm{m}$ of spatial resolution). The five topographic factors and fault density (continuous variables) were reclassified according to Natural Breaks (Jenks) while the land use/cover and the lithology (categorical variables) were reclassified according to their normal units (Fig. 3, $\boldsymbol{c}, \boldsymbol{d}$ ).

The landslide inventory is the main component of any landslide susceptibility assessment. Subsequently, an inventory of all landslides is carried out. The characteristics, spatial mapping, and inventory of different landslides type in the hillslopes of Bujumbura were first identified using the interpretation of high-resolution aerial ortho-photographs $(0.5 \mathrm{~m})$ and the google earth and then completed and validation with intensive fieldwork (Fig. 4). A new data catalog with 584 landslides is provided (Fig. 4) classified according to [17] in flowslides, planer/rotational slides, and rockslides.

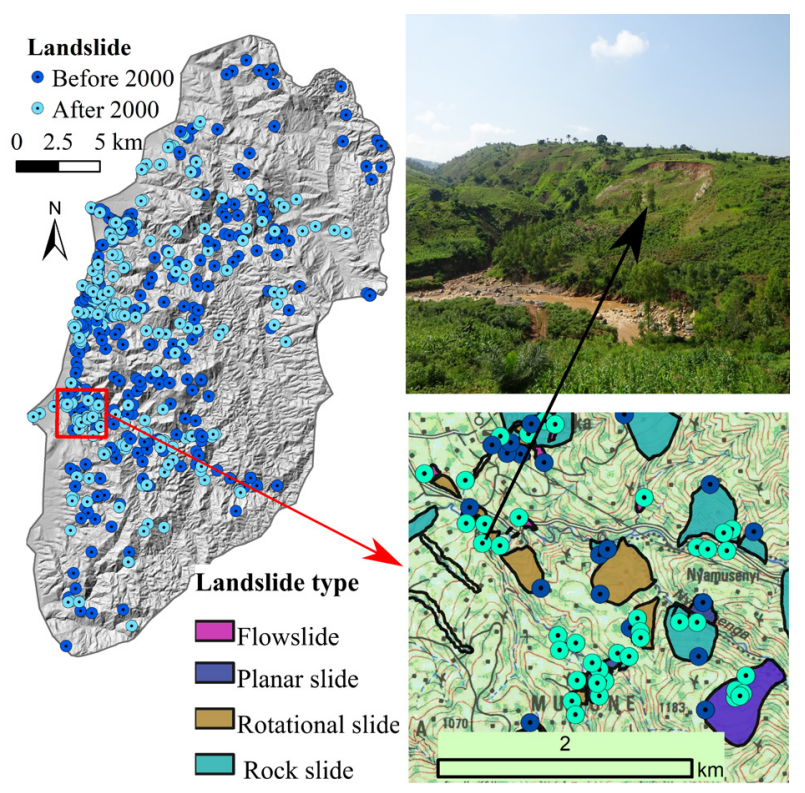

Fig. 4. Location of landslides in the study area

To perform the landslide susceptibility, the Weights of Evidence method is used. It is a probabilistic approach that involves determining the probability of a region undergoing future landslides. This indirect mapping approach characterizes the extent of occurrence of landslides based on their conditioning factors [18]. In order to achieve this model, let's integrate landslides conditioning factors into GIS and then converted to raster integer before being subjected to the statistical treatments. Let's calculate then the landslides posterior probability using relationships between independent predictive variables and landslide distribution.

Let's calibrate the model with a part of the landslide inventory (training sites) and another part for validation (testing sites). According to [19], there is no universal rule for selecting the ratio of testing/training dataset. In our case, the model we used $50 \%$ of landslides (284 training sites) and validated with the remaining $50 \%$ (284 testing sites). The calibration landslides were not selected randomly but according to the period of spatial occurrence i.e. triggered before the 2000 s and therefore independent of testing landslides initiated afterward. The differentiation of landslides timing was done using Google Earth imageries available from the 2000s to the present and field investigation.

The model performance was calculated using the Weights of Evidence model and GIS. To compare the landslides factors, the performance by removing one by one was calculated, as was performed in Costa Viola mountain ridge [20]. Low accuracy indicated that the removed factor is more important and vice-versa.

For validation, let's automatically calculate the Conditional Independence Ratio (CIR) to validate if landslides controlling factors are independent of each other. CIR $>1$ indicated that there was independence between variables in the model [21]. Finally, let's calculate the Area 
under Curves (AUC) using Success Rate Curve (SRC) and Predictive Rate Curve (PRC). According to [21], the accuracy $\geq 50 \%$ is acceptable for landslide susceptibility modeling. The data collection and treatments carried out for landslide susceptibility mapping are drawn flowchart of the Fig. 5.

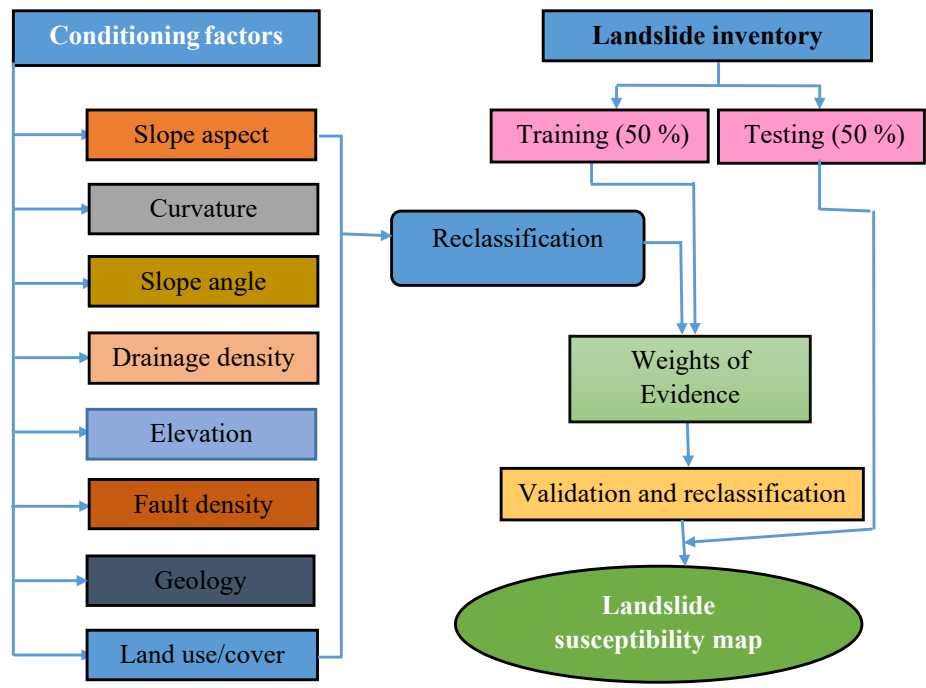

Fig. 5. Flowchart of methodology used in this study

\section{Results}

The recombination of the independent variables shows the ascending order is as follows the drainage density, the land use/cover, the lithology, the fault density, the slope angle, the curvature, the elevation, and the slope aspect. These are the landside controlling factors in the study area. This result is broadly similar to the previous study, except that the order often changes [13]. For example, the lithology, the fault density and the drainage were highlighted as the main controlling factors previously at a regional scale and locally [5, 13].

The relatively low weighting of the slope angle would be that shallow landslides were not considered in this study as training datasets (Fig. 4). In fact, it is dealt with landslides initiated before the 2000s for training sites. Or old landslides are deep-seated because, in the landscape, shallow landslides disappeared in few years (generally two) due to rapid erosion and rapid weathering processes [4], whereas they are more gravity-induced and sensitive to climatic and geoenvironmental constraints [22]. This low correlation of slope angle to deep-seated landslides comes to support the reason that in the hillslopes of Bujumbura, old deep-seated landslides are not especially gravity-driven but rather to other facets such as the geodynamics process as proved in the region [10]. In this study, let's evidence it through a good correlation of landslide distribution with the fault system. The land use/cover not considered previously in the multi-criteria analysis [13] shown however a high control of landslides. This shows that it is a significant landslide controlling factor that should not be ignored.

The low controlling factors are the elevation and the slope aspect. The lack of slope aspect control in landslide occurrence was previously predicted in a regional study [12]. The own reason is that the region belongs to the tropical climate where slopes are exposed to the sunlight in the same way and therefore receive the same quantity of precipitations. There is no obvious variability in landslide occurrence associated with the slope aspect. For elevation, the lack of landslide control would be related to the small scale of the study which implies insignificant climatic variations.

The CIR calculated is $1.1(>1)$ i. e. the variables are independent [21]. The Weights of Evidence experiment is $0.706 \mathrm{i}$. e. the model predicts known landslides (before the 2000s) with an accuracy of $70.6 \%$. This is a satisfactory value as it is more than $50 \%$ [21]. The corresponding probability map was then generated. In order to simplify the resulting probability map, the probability values were reorganized into five classes using the Natural Breaks (Jenks) classification method designed to determine the best arrangement of values in different classes (Fig. 6). 


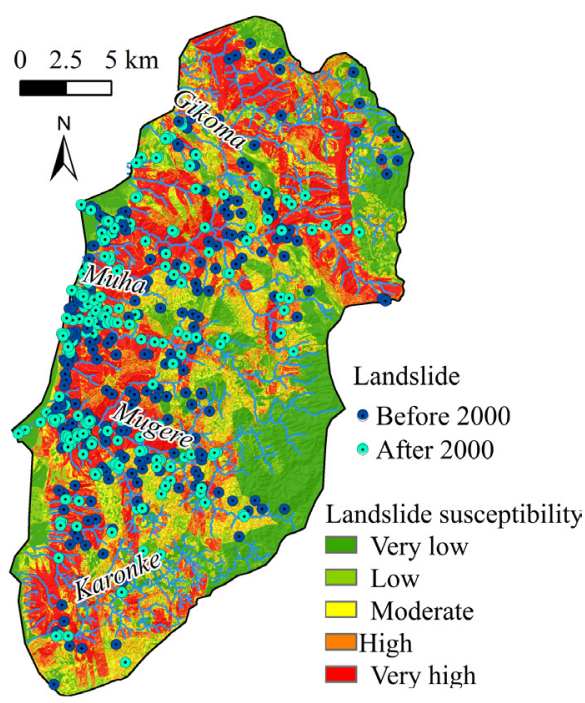

Fig. 6. Landslide susceptibility map

In order to test the validity of the Weights of Evidence model, let's analyse the posterior probability map using the Predictive Rate Curve (PRC), which are the most important means of evaluating the landslide susceptibility map. The PRC is $76 \%$ for predicting landslide initiated after the 2000s (Fig. 7). This value ( $>50 \%$ ) is valid to assess the landslide susceptibility [21].

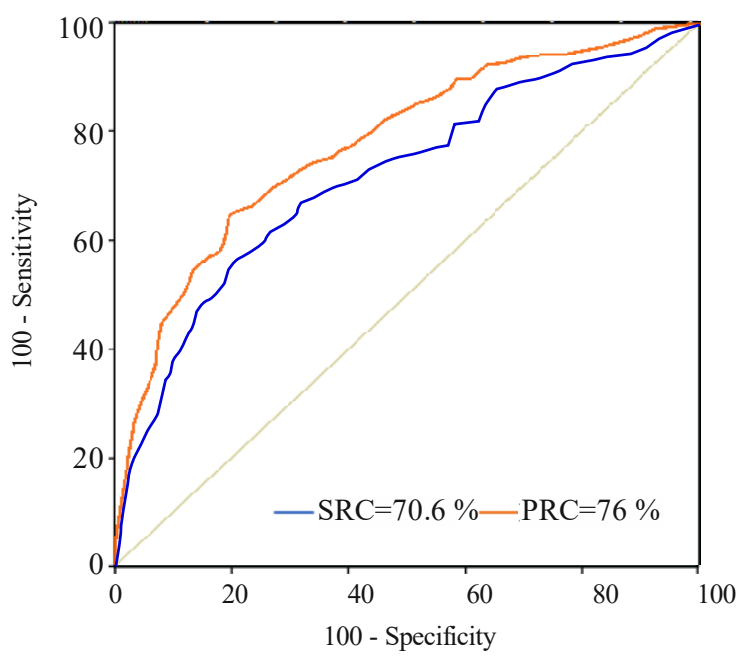

Fig. 7. Success/Predictive Rate Curve for model performance

The Weights of Evidence model showed that the areas of the very low, low, moderate, high, and very high landslide susceptibility represent $23 \%, 11 \%, 16 \%, 19 \%$, and $31 \%$ respectively. The landslide distribution showed that $19 \%$ and $50 \%$ of the landslide inventory (post-2000) fall in the high and very high landslide susceptibility areas respectively (Fig. 8).

This allows to validate the model performance. The very high landslide susceptibility is supported by several destructions observed in the hillslopes of Bujumbura (roads, schools, houses, hydroelectric power stations, markets, sanitation, etc).

The susceptibility map of Fig. 6 shows the western part more susceptible to future slope failures. In this region, the areas around the main rivers are more prone to landslides. However, it is part very stressed for the expansion of the city of Bujumbura. Authorities must be careful when managing the new areas. 


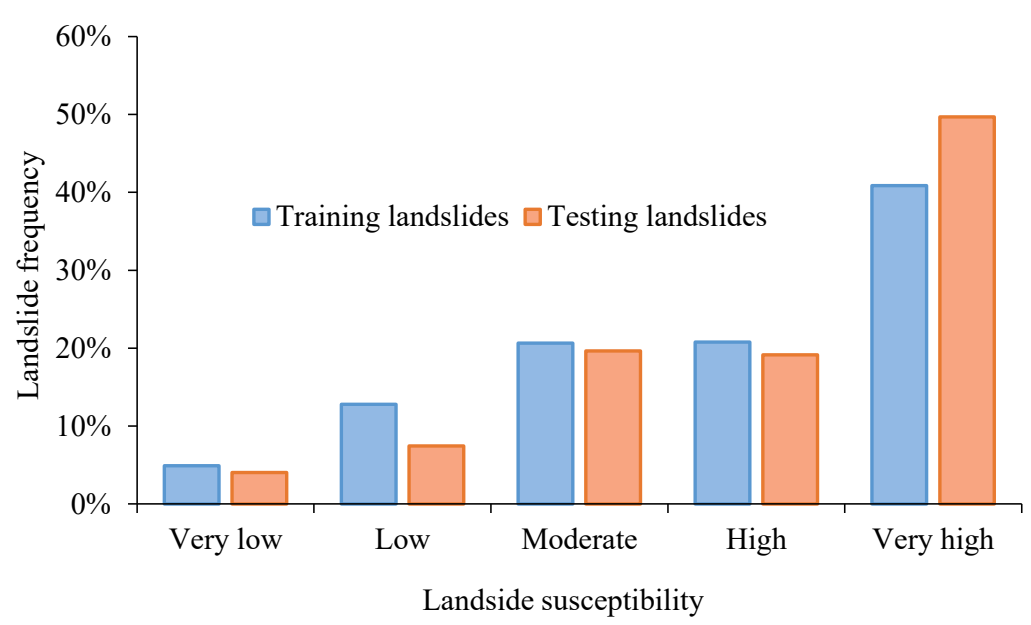

Fig. 8. Percentage of landslides occurred in each landslide susceptibility class

\section{Discussion of experimental results}

The inventory of 568 landslides over $491 \mathrm{~km}^{2}$ means a density of $\sim 1.2$ landslide $/ \mathrm{km}^{2}$. This figure is higher than what is known, i. e. 243 landslides all over Western Burundi in which 89 are only located in the study area [11]. The susceptibility map shows that the areas susceptible to future landslide initiation are $50 \%$ of the study area (Fig. 6). The proportion is very high for a densely populated area and therefore local authorities must closely follow the landslide hazard.

The available susceptibility maps were performed using expert methods $[11,13]$. They took into account some predisposition factors such as the slope angle, geology, and drainage [11]. The present study used the statistical method with eight conditioning factors (Fig. 2, 3). For model performance, previous studies have not calculated it for comparison with the new approach. Let's note only that the number of landslides used for validation is more than six times lower than the one used in the present study.

This research was limited to the development and analysis of the susceptibility map from the available data. In order to reduce the damages, a landslide risk/vulnerability assessment must be envisaged. To implement it, new data collection on the exposure will be needed and will require time and money.

The method used is effective. The disadvantage of this study is that predisposition factors while ignoring the triggering factors are used. It is known that in the NTK Rift region, rainfall is the main landslide trigger [2]. The insertion of the rainfall component would increase the reliability of the prediction map. To deal with this problem, it would be better to install weather stations in the study area in order to collect rainfall density data.

The present study is the first step for the development of the landslide risk/vulnerability map useful in disaster risk reduction strategies. The difficulty with this approach as well as other mathematical models is that they provide a posteriori probability at a specific threshold, for our case $76 \%$. Even if the value is statistically significant, the remaining $24 \%$ cannot be ignored. Moreover, the model does not integrate the temporal aspect, we do not know when the landslide will occur to take precautions in real-time. Therefore, the early warning system must always remain vigilant to ensure a strict follow-up of landslides.

\section{Conclusion}

In order to predict/reduce potential slope instabilities and their damages in the hillslopes of Bujumbura, research on the landslides inventory, characterization, and susceptibility assessment has been carried out. The landslide susceptibility achieved with 568 landslides and eight conditioning factors is assessed. The landslide susceptibility is valid at $76 \%$ to control future landslides. Most areas susceptible to landslides are on the west side especially around the main rivers crossing the city. 
This study was limited to a general assessment of landslide susceptibility but could be extended to risk/vulnerability assessment. The provided landslide susceptibility map will help urban planners for disaster risk reduction strategies and billions of dollars lost every year could be saved.

\section{Acknowledgments}

This study was carried out within the framework of a doctoral thesis financed by bilateral cooperation between the Republic of Burundi and the Kingdom of Morocco via the Moroccan Agency for International Cooperation (AMCI) and the Bureau des Bourses d'Etudes et des Stages (BBES). Desire Kubwimana has obtained fundings for field research from ARES/PFS, RESIST, and GeoRisCA. We thank all these funding partners.

\section{References}

[1] Broeckx, J., Vanmaercke, M., Duchateau, R., Poesen, J. (2018). A data-based landslide susceptibility map of Africa. EarthScience Reviews, 185, 102-121. doi: https://doi.org/10.1016/j.earscirev.2018.05.002

[2] Monsieurs, E., Kirschbaum, D., Thiery, W., van Lipzig, N., Kervyn, M., Demoulin, A. et. al. (2017). Constraints on Landslide-Climate Research Imposed by the Reality of Fieldwork in Central Africa. 3rd North American Symposium on Landslides, 158-168. Available at: https://orbi.uliege.be/handle/2268/213093

[3] Dille, A., Kervyn, F., Mugaruka Bibentyo, T., Delvaux, D., Ganza, G. B., Ilombe Mawe, G. et. al. (2019). Causes and triggers of deep-seated hillslope instability in the tropics - Insights from a 60-year record of Ikoma landslide (DR Congo). Geomorphology, 345, 106835. doi: https://doi.org/10.1016/j.geomorph.2019.106835

[4] Dewitte, O., Dille, A., Depicker, A., Kubwimana, D., Maki Mateso, J.-C., Mugaruka Bibentyo, T. et. al. (2021). Constraining landslide timing in a data-scarce context: from recent to very old processes in the tropical environment of the North Tanganyika-Kivu Rift region. Landslides, 18 (1), 161-177. doi: https://doi.org/10.1007/s10346-020-01452-0

[5] Jacobs, L., Dewitte, O., Poesen, J., Maes, J., Mertens, K., Sekajugo, J., Kervyn, M. (2017). Landslide characteristics and spatial distribution in the Rwenzori Mountains, Uganda. Journal of African Earth Sciences, 134, 917-930. doi: https:// doi.org/10.1016/j.jafrearsci.2016.05.013

[6] Maes, J., Kervyn, M., de Hontheim, A., Dewitte, O., Jacobs, L., Mertens, K. et. al. (2017). Landslide risk reduction measures: A review of practices and challenges for the tropics. Progress in Physical Geography: Earth and Environment, 41 (2), $191-221$. doi: https://doi.org/10.1177/0309133316689344

[7] Wilson, A. M., Jetz, W. (2016). Remotely Sensed High-Resolution Global Cloud Dynamics for Predicting Ecosystem and Biodiversity Distributions. PLOS Biology, 14 (3), e1002415. doi: https://doi.org/10.1371/journal.pbio.1002415

[8] Nobile, A., Dille, A., Monsieurs, E., Basimike, J., Bibentyo, T., d' Oreye, N. et. al. (2018). Multi-Temporal DInSAR to Characterise Landslide Ground Deformations in a Tropical Urban Environment: Focus on Bukavu (DR Congo). Remote Sensing, 10 (4), 626. doi: https://doi.org/10.3390/rs10040626

[9] Robinson, T. R., Rosser, N., Walters, R. J. (2019). The Spatial and Temporal Influence of Cloud Cover on Satellite-Based Emergency Mapping of Earthquake Disasters. Scientific Reports, 9 (1). doi: https://doi.org/10.1038/s41598019-49008-0

[10] Depicker, A., Govers, G., Jacobs, L., Campforts, B., Uwihirwe, J., Dewitte, O. (2020). Interactions between deforestation, landscape rejuvenation, and shallow landslides in the North Tanganyika - Kivu Rift region, Africa. Earth Surface Dynamics Discussions. doi: https://doi.org/10.5194/esurf-2020-87

[11] Nibigira, L., Draidia, S., Havenith, H.-B. (2015). GIS-Based Landslide Susceptibility Mapping in the Great Lakes Region of Africa, Case Study of Bujumbura Burundi. Engineering Geology for Society and Territory - Volume 2, 985-988. doi: https:// doi.org/10.1007/978-3-319-09057-3_172

[12] Jacobs, L., Dewitte, O., Poesen, J., Sekajugo, J., Nobile, A., Rossi, M. et. al. (2018). Field-based landslide susceptibility assessment in a data-scarce environment: the populated areas of the Rwenzori Mountains. Natural Hazards and Earth System Sciences, 18 (1), 105-124. doi: https://doi.org/10.5194/nhess-18-105-2018

[13] Désiré, K., Lahsen, A. B., Mahfoud, B., Olivier, D., Abdellah, A., Tarik, B. (2018). Landslides susceptibility assessment using AHP method in Kanyosha watershed (Bujumbura-Burundi): Urbanisation and management impacts. MATEC Web of Conferences, 149, 02071. doi: https://doi.org/10.1051/matecconf/201814902071

[14] Moeyersons, J., Trefois, P. (2012). La protection du site CURGO - Kabezi -Bujumbura contre les risques hydrologiques dans le bassin de la rivière Nyabage: Etude de formulation d'une operation de conservation. MRAC Tervuren. Available at: https:// repository.tudelft.nl/islandora/object/uuid:3e6a844d-e90e-4234-b83e-6215846ca652?collection=research 
[15] Delvaux, D., Mulumba, J.-L., Sebagenzi, M. N. S., Bondo, S. F., Kervyn, F., Havenith, H.-B. (2017). Seismic hazard assessment of the Kivu rift segment based on a new seismotectonic zonation model (western branch, East African Rift system). Journal of African Earth Sciences, 134, 831-855. doi: https://doi.org/10.1016/j.jafrearsci.2016.10.004

[16] Van Westen, C. (2007). Introduction to landslides Part 1: Types and causes. International Institute for Aerospace Survey and Earth Sciences (ITC). Enschede. Available at: https://ru.scribd.com/document/333441109/Landslides-Types-and-Causes\#

[17] Hungr, O., Leroueil, S., Picarelli, L. (2014). The Varnes classification of landslide types, an update. Landslides, 11 (2), $167-194$. doi: https://doi.org/10.1007/s10346-013-0436-y

[18] Soeters, R., Van Westen, C. J. (1996). Slope instability recognition, analysis, and zonation. National Academy Press, $129-177$. Available at: https://research.utwente.nl/en/publications/slope-instability-recognition-analysis-and-zonation

[19] Pradhan, B., Lee, S. (2010). Landslide susceptibility assessment and factor effect analysis: backpropagation artificial neural networks and their comparison with frequency ratio and bivariate logistic regression modelling. Environmental Modelling \& Software, 25 (6), 747-759. doi: https://doi.org/10.1016/j.envsoft.2009.10.016

[20] Iovine, G. G. R., Greco, R., Gariano, S. L., Pellegrino, A. D., Terranova, O. G. (2014). Shallow-landslide susceptibility in the Costa Viola mountain ridge (southern Calabria, Italy) with considerations on the role of causal factors. Natural Hazards, 73 (1), 111-136. doi: https://doi.org/10.1007/s11069-014-1129-0

[21] Sawatzky, D., Raines, G., Bonham-Carter, G. (2010). Spatial Data Modeller. Available at: https://www.ige.unicamp.br/sdm/ ArcSDM10/source/ReadMe.pdf

[22] Sidle, R. C., Bogaard, T. A. (2016). Dynamic earth system and ecological controls of rainfall-initiated landslides. EarthScience Reviews, 159, 275-291. doi: https://doi.org/10.1016/j.earscirev.2016.05.013

How to cite: Kubwimana, D., Ait Brahim, L., Abdelouafi, A. (2021). A new approach in the development and analysis of the landslide susceptibility map of the hillslopes of Bujumbura, Burundi. EUREKA: Physics and Engineering, 3, 26-34. doi: https://doi.org/ 10.21303/2461-4262.2021.001724 